This is the final peer-reviewed accepted manuscript of:

Surface modified nano-SiO2 enhances dielectric properties of stator coil insulation for HV motors

in IEEE Transactions on Dielectrics and Electrical Insulation, vol. 27, no. 3, pp. 10291037, June 2020

The final published version is available online at:

https://doi.org/10.1109/TDEI.2020.008736

Rights / License:

The terms and conditions for the reuse of this version of the manuscript are specified in the publishing policy. For all terms of use and more information see the publisher's website.

This item was downloaded from IRIS Università di Bologna (https://cris.unibo.it/)

When citing, please refer to the published version. 


\title{
Surface Modified Nano-SiO 2 Enhances Dielectric Properties of Stator Coil Insulation for HV Motors
}

\author{
Zhipeng Lei, Rujia Men, Fei Wang, Yuanyuan Li and Jiancheng Song \\ Shanxi Key Laboratory of Mining Electrical Equipment and Intelligent Control, National and Provincial Joint Engineering \\ Laboratory of Mining Intelligent Electrical Apparatus Technology \\ Taiyuan University of Technology, Taiyuan 030024, China \\ Tohid Shahsavarian and Chuanyang Li \\ Electrical Insulation Research Center, Institute of Materials Science, Electrical and Computer Engineering \\ University of Connecticut, Storrs, CT 06269, USA \\ Davide Fabiani \\ Department of Electrical, Electronic, and Information Engineering \\ University of Bologna, Bologna 40136, Italy
}

\begin{abstract}
Nano-SiO ${ }_{2}$ particles were doped into epoxy resin (EP) to fabricate the main insulation used for high voltage (HV) motors. The EP-based nanocomposite with different mass ratios of nano-SiO $\mathrm{S}_{2}$ particles $(0.5,1,2.5$, and $5 \mathrm{wt} \%)$ were prepared. Surface morphology and conductivity of samples were tested, and $\mathrm{AC}$ breakdown strength was measured at different temperatures. The mechanisms for the tailoring of dielectric properties of EP were discussed. The optimal doping scheme $(0.5 \mathrm{wt} \%)$ was selected and used as the base material in preparation of a stator coil insulation for $6 \mathrm{kV}$ motors. The dielectric properties, including dielectric loss and leakage current as well as partial discharge, were tested, and the potential application of nano-SiO $\mathrm{O}_{2}$ particles in the stator coil insulation of HV motors was discussed. The test results showed that the doped nano- $\mathrm{SiO}_{2}$ particle into dielectric composite used as the main insulation material for HV motors can be an optimal candidate to improve the above mentioned properties especially dielectric losses and electrical breakdown strengths. The results in this paper offer references and a guiding significance for the application of nano-SiO insulation of $\mathrm{HV}$ motors.
\end{abstract}

Index Terms - Nanocomposite; epoxy resin; nano silica; dielectric strength; HV motors.

\section{INTRODUCTION}

THE increase in motor capacity and the reduction of motor size have always been a contradiction. This problem is more prominent for HV motors operating in some special environment, e.g. in the coal mine, the vessel or the highspeed train. Due to limited operating environment in special environment, it is very difficult to achieve high capacity with relative smaller size for HV motors [1]. The key parameter which allows the determination of the size of motors is the thickness of the main insulation of the stator coils, which is also the most vulnerable part of HV motors [2]. Therefore, in order to improve the electrical properties of the main insulation, the use of proper materials is a critical issue for $\mathrm{HV}$ motors since it could allow the realization of HV motors with larger capacity and smaller size.

The most common dielectric materials used in the main insulation of HV motors are: tung-maleic anhydride adhesive epoxy resin (TMEP) and tung-maleic epoxy resin glass mica paper tape (EPMT). EPMT is mainly made of powder mica paper, glass-fiber fabric, and adhesive resin. Powder mica paper and glass-fiber fabric are inorganic materials with good electrical properties. Therefore, the applicability of EPMT in HV motors mainly depends on the characteristics of the adhesive resin. Epoxy resin is not only the main component of adhesive resin in mica tape but also the main component of impregnating resin used during the process of vacuum pressure impregnation of main insulation. Therefore, the key to improving the properties of the main insulation for $\mathrm{HV}$ motors lies on the improvement of epoxy resin properties [3].

Doping of nanofillers is a useful way to tailor the property of dielectric materials $[4,5]$. Studies show that nanoparticles added to the insulation materials are mainly distributed among the polymer chains and play a positive role in improving the 
property of insulating materials [6-8]. Weidner et al modified the epoxy mica with different contents of nano- $\mathrm{SiO}_{2}$. They found that the electrical and thermal properties are enhanced by nano patricals [9]. Dettmer et al proposed an idea to wind a motor coil with nanoparticles filled XLPE insulation layers to accomplish a "cable-wound motor". The electric field strength of the coil increased by approximately 2.3 times [10]. However, since the mechanical modulus of polyethylene resin is small, the winding can easily loosen or vibrate under the action of a large electromagnetic force during operation [10].

In this paper, surface-modified nano- $\mathrm{SiO}_{2}$ particles are doped in epoxy resin, and samples with different doping ratios were prepared. Based on the dielectric property measurement results, the optimal doping ratio $(0.5 \mathrm{wt} \%)$ was selected and used as the base material in preparation of a $6 \mathrm{kV}$ stator coil. The dielectric properties of this bar were tested and the potential application of nano- $\mathrm{SiO}_{2}$ particles in the stator coil insulation of $\mathrm{HV}$ motors was discussed.

\section{EXPERIMENTAL}

\subsection{PREPARATION OF SAMPLES}

The epoxy resin used in this paper is a low molecular bisphenol A epoxy resins (E-51). The epoxy value is $0.48-0.51$ and the viscosity is $11000-14000 \mathrm{mPa} \cdot \mathrm{s} / 25^{\circ} \mathrm{C}$. The diameter of the nano- $\mathrm{SiO}_{2}$ ranges from $7 \mathrm{~nm}$ to $50 \mathrm{~nm}$. The nano- $\mathrm{SiO}_{2}$ based nanocomposite was prepared with nano- $\mathrm{SiO}_{2}$ mass ratio of $0.5,1,2.5$ and $5 \mathrm{wt} \%$. The small-sized samples are labeled as S_0, S_0.5, S_1, S_2.5, and S_5, with $10 \mathrm{~mm}$ of diameter and $0.3 \mathrm{~mm}$ of thickness. The curing agent is methyl hexahydrophthalic anhydride (MHHPA) and the release agent used for the demolding of samples is GA-7500 solvent-based release agent. The preparation process of nano- $\mathrm{SiO}_{2}$ based epoxy resins is described as follows: (1) Clean the mold with acetone and absolute ethanol for two times and dry the mold at $80{ }^{\circ} \mathrm{C}$ for 30 minutes. (2) Spray the liquid release agent evenly on the mold surface and place the mold in a drying oven for at least 3 hours at $120{ }^{\circ} \mathrm{C}$. (3) Dry the nano- $\mathrm{SiO}_{2}$ particles at $120^{\circ} \mathrm{C}$ for 12 hours. (4) Place the epoxy resin in a drying oven at $60{ }^{\circ} \mathrm{C}$ for 30 minutes. Mix the nano- $\mathrm{SiO}_{2}$ into the epoxy resins and mechanically stir with a speed of $4000 \mathrm{r} / \mathrm{min}$ for 1 hour at $60{ }^{\circ} \mathrm{C}$. (5) Add the hardener, the accelerator to the epoxy resin accordingly and stir the composite with a speed of $3000 \mathrm{r} / \mathrm{min}$ at $80{ }^{\circ} \mathrm{C}$ for 5 minutes. After that, place the mixtures in a vacuum drying oven at $80{ }^{\circ} \mathrm{C}$ for about 30 minutes for the vacuuming process. (6) Pour the mixed liquid into the preheated mold and place the mold in the drying oven at $120^{\circ} \mathrm{C}$ for 90 minutes. Finally, take out the mold and cool it down naturally. The manufacturing process can be depicted in Figure 1.

A stator coil of the $6 \mathrm{kV}$ motor using epoxy with a doped nano- $\mathrm{SiO}_{2}$ ratio of $0.5 \mathrm{wt} \%$ was prepared according to the industrial preparation method in a motor repairing workshop [11]. The insulating material of the stator coil was mica tape doped with $0.5 \mathrm{wt} \%$ nano- $\mathrm{SiO}_{2}$. The mica tape has a mica content of $82 \pm 6 \mathrm{~g} / \mathrm{m}^{2}$, a glass cloth content of $36 \pm 4 \mathrm{~g} / \mathrm{m}^{2}$, and an adhesive content of $74 \pm 9 \mathrm{~g} / \mathrm{m}^{2}$. The mica tape has a width of $25 \pm 1 \mathrm{~mm}$ and a thickness of $0.14 \pm 0.02 \mathrm{~mm}$. This stator coil was measured and a commercial $6 \mathrm{kV}$ stator coil without doping with nanoparticles was also measured as a comparison. It is worth noting that the stator coils used in this experiment are the commercialized $6 \mathrm{kV}$ coils and no semi-conductive coating was applied on the surface of these coils.

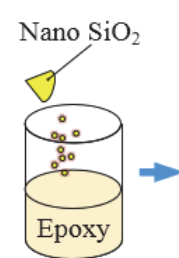

(a)

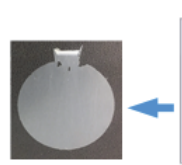

(h)

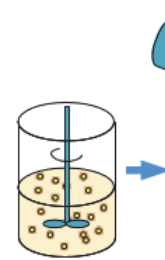

(b)

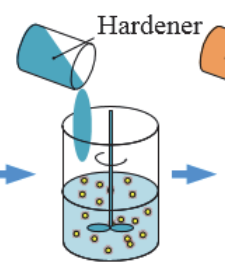

(c)
Accelerator

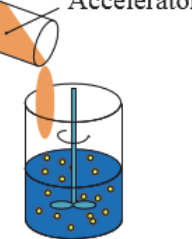

(d)

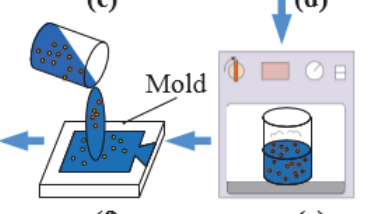

(e)

Figure 1. Preparation process of $\mathrm{EP} / \mathrm{SiO}_{2}$ composites. (a) Weighing appropriate amount of epoxy resin, (b) adding SiC fillers, (c) adding hardener and stirring at $60^{\circ} \mathrm{C}$, (d) adding curing agent and stirring at room temperature, (e) vacuum degassing, (f) surface coating on spacers, (g) curing at room temperature for $12 \mathrm{~h}$, and (h) curing at $80^{\circ} \mathrm{C}$ for $12 \mathrm{~h}$.

\subsection{CHARACTERIZATION}

The surface morphology was observed using SEM (JSM6700F, Nippon Electronics Co., Ltd.).

The bulk conductivity measurement was carried out using a high resistance meter (Keithley 6517B). At first, samples with a thickness of $300 \mu \mathrm{m}$ were electrically short-circuited for 5 minutes to eliminate internal charges and then a constant DC electric field of $2 \mathrm{kV} / \mathrm{mm}$ was applied to the samples for 10 minutes with the leakage current being recorded.

The dynamic thermo-mechanical analysis (DMA) test was performed using a Netzsch DMA242, Germany. During the measurement, the rate of change of temperature during heating and cooling was $5{ }^{\circ} \mathrm{C} / \mathrm{min}$ between 30 and $200{ }^{\circ} \mathrm{C}$. The force and the displacement were $3 \mathrm{~N}$ and $10 \mu \mathrm{m}$ at 1,5 , and $10 \mathrm{~Hz}$.

DC breakdown tests were performed on a dielectric strength tester with controllable temperature using film samples with a thickness of about $300 \mu \mathrm{m}$. The samples were sandwiched between two copper cylindrical electrodes with a diameter of $20 \mathrm{~mm}$ and immersed in the oil to avoid surface flashover. The applied DC voltage was increased at a rate of $50 \mathrm{~V} / \mathrm{s}$ to breakdown. The temperatures of oil during measurement were $20,40,80,120,140,155$ and $180^{\circ} \mathrm{C}$. Ten points were tested for each sample and a two-parameter Weibull distribution was used to analyze the obtained data.

The trap distribution of samples was calculated according to the space charge distribution at the depolarization phase as is reported in literature [12]. Space charge decay characteristics of samples during depolarization were measured by a pulsed electro-acoustic (PEA) technique, and the current density was obtained through the average charge density of samples. Assuming that the released carriers are no longer captured by 
traps, the trap level, $E_{t}$, and the trap level density, $N\left(E_{t}\right)$, can be calculated respectively according to the following equations:

$$
\begin{gathered}
E_{t}=k T \ln (v t) \\
N\left(E_{t}\right)=\frac{\eta_{2}}{\eta_{1}} \frac{t}{\tau} e^{-t / \tau}
\end{gathered}
$$

where $k$ is Boltzmann's constant, $8.61 \times 10^{-5} \mathrm{eV} / \mathrm{K} ; T$ is the absolute temperature; $v$ is the electronic vibration frequency, $3 \times 10^{12} \mathrm{~Hz} ; \eta_{l}$ is $q d k T / 4, q$ is the quantity of electric charge, $1.6 \times 10^{-19} \mathrm{C} ; \eta_{2}$ is $1.2 \times 10^{-10} \mathrm{~A} / \mathrm{d} ; \tau$ and $A$ are the constants in the exponential function; $\mathrm{d}$ is the thickness of specimen.

The dielectric loss measurement was performed using an AI6000 dielectric loss instrument whose schematic diagram is shown in Figure 2. The output voltage was $0 \sim 10 \mathrm{kV}, 50$ $\mathrm{Hz}$ sinusoidal voltage, and the dielectric loss measurement accuracy was $\pm($ result $\times 1 \%+0.00040)$. The temperature control box was used to control the temperature of the coil, with an accuracy of $\pm 1 \% \mathrm{~F} \cdot \mathrm{S}$. Before the measurement, the conductor of the coil was connected to the high voltage end of AI6000, and then the copper foil was wounded as a measuring electrode in a straight section of the coil. The copper foil had a width of $50 \mathrm{~mm}$ and a thickness of $0.2 \mathrm{~mm}$. Secondly, the copper foil was wrapped as a protective electrode with a distance of $4 \mathrm{~mm}$ away from both sides of the measuring electrode. The width of the copper foil for the protective electrode was $20 \mathrm{~mm}$, with the same thickness as the measuring electrode. Finally, the measuring electrode was connected to the measuring section of AI6000 via a shielded cable, while the protective electrode was grounded. Before the measurement, the temperature was set to a constant value and kept for $30 \mathrm{~min}$, then the voltage was increased to the desired value and the dielectric loss of the stator coil was measured.

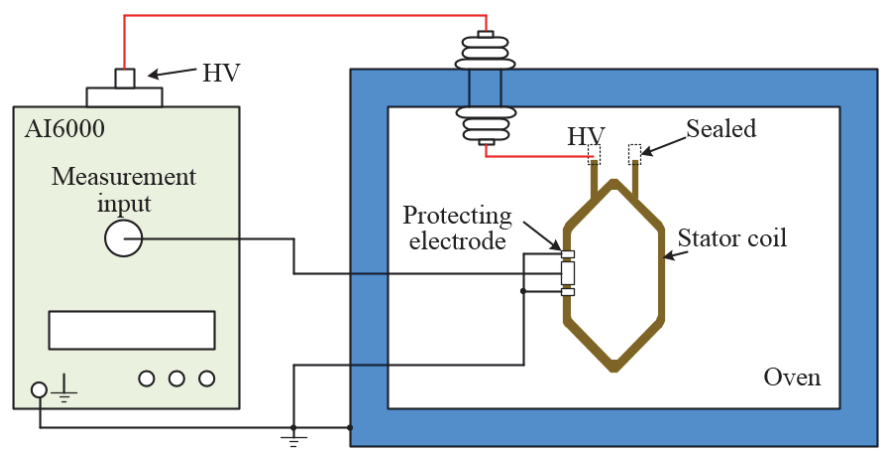

Figure 2. Measurement systems of dissipation factor for stator coils.

The PD was measured by a PD analyzer (OMICRON MPD600) whose experimental setup is shown in Figure 3. A High Frequency Current Transformers (HFCT) sensor (HVPD HFCT 100/50) was clipped around the ground wire to measure partial discharge pulses.

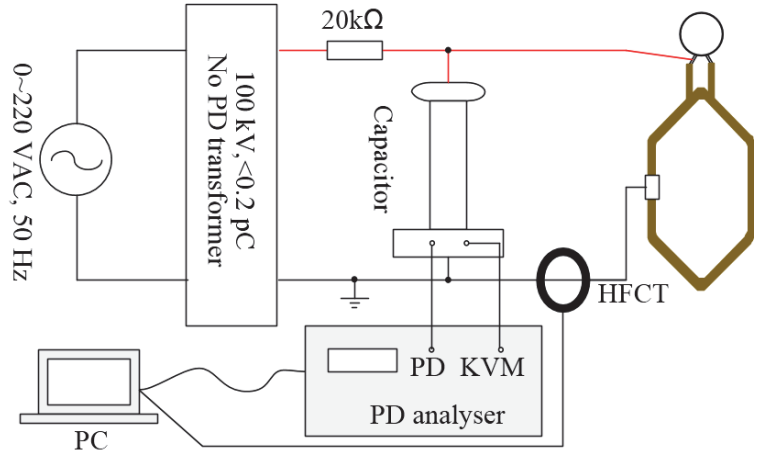

Figure 3. Schematic diagram of PD measurement system.

\section{RESULTS AND DISCUSSION}

\subsection{SURFACE MORPHOLOGY}

The morphology of the experimental samples is shown in Figure 4 . The surface is very smooth and there are no local mutation of surface roughness can be found in Figure 4 (a). It is observed from Figure 4 (b), (c) and (d) that the $\mathrm{SiO}_{2}$ nanoparticles are uniformly distributed in the epoxy matrix at low nanoparticle loadings $(0.5,1$, and $2.5 \mathrm{wt} \%)$. When the nano- $\mathrm{SiO}_{2}$ content increases to $5 \mathrm{wt} \%$, a small amount of micro-sized aggregates appear (as shown in Figure 4 (e)). As concluded in previous researches, these aggregates of nanoparticles are probably the origins of material degradation of the nanocomposites $[13,14]$.

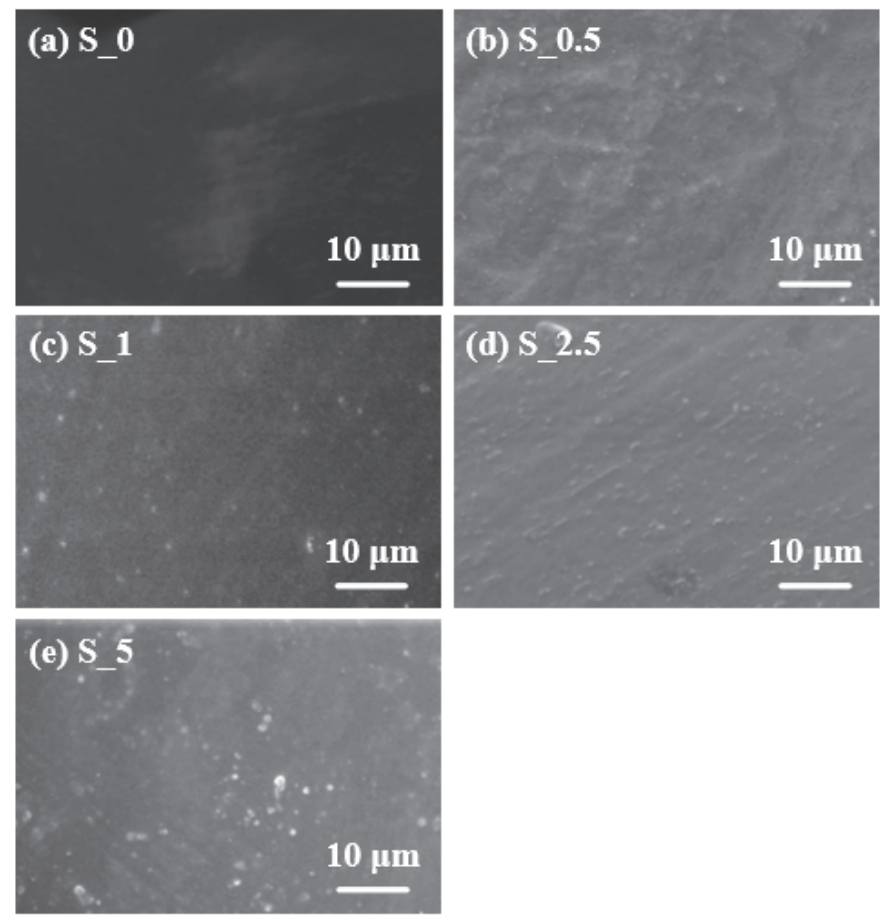

Figure 4. SEM images of experimental samples.

\subsection{CONDUCTIVITY ANALYSIS}

Figure 5 shows the DC conductivity of EP nanocomposites at room temperature. The conductivity of EP nanocomposites initially decreases and then increases with the increase of 
nanoparticles. When the content of nanoparticles is $0.5 \mathrm{wt} \%$ and $1 \mathrm{wt} \%$, the conductivity of EP nanocomposites is lower than that of pure EP. The bulk conductivity of S_2.5 is almost the same as the S 0. However, it is worth noting that when the doping ratio is $5 \mathrm{wt} \%$, the bulk conductivity increases up to $2.3 \times 10^{14} \mathrm{~S} / \mathrm{m}$, which is 2.5 times larger than S_0.5 and S_1.

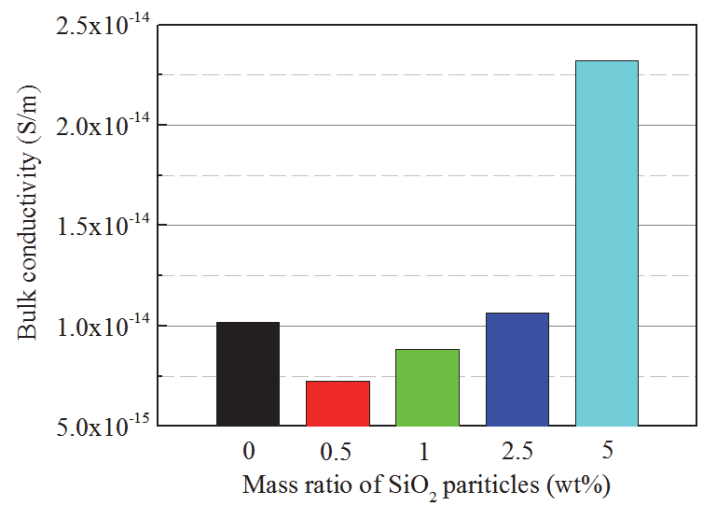

Figure 5. DC bulk conductivity of $\mathrm{EP} / \mathrm{SiO} 2$ composites.

\subsection{DYNAMIC MECHANICAL ANALYSIS}

Dynamic mechanical analysis (DMA) is based on the modulus of elasticity of the material to determine the glass transition temperature $\left(T_{g}\right)$. Therefore, from the viewpoint of molecular chain motion, when the temperature rises to $T_{g}$, the polymer segment starts to move and the material enters a high elastic state. As can be seen from Figure 6, the $T_{g}$ of different samples ranged from $130{ }^{\circ} \mathrm{C}$ to $140{ }^{\circ} \mathrm{C}$. When the doping amount is $0.5 \mathrm{wt} \%$, the $T_{\mathrm{g}}$ shows the highest value (about $140^{\circ} \mathrm{C}$ ), and when the doping amount is further increased, the $T_{\mathrm{g}}$ tends to decrease. This phenomenon is likely imputed to the interfaces in the insulation system, which can play a decisive role in $T_{g}$ improvement. A small amount of nanoparticles $(0.5$ $\mathrm{wt} \%)$ evenly distributed in the matrix can introduce a large number of interfaces, which enhances the physical and chemical cross-linking of the system and limits further the movement of the polymer molecular chains and increases the $T_{g}$. As the nano-content increases, agglomeration occurs between particles, and the interface regions can overlap, resulting in an additional free volume in the epoxy matrix.

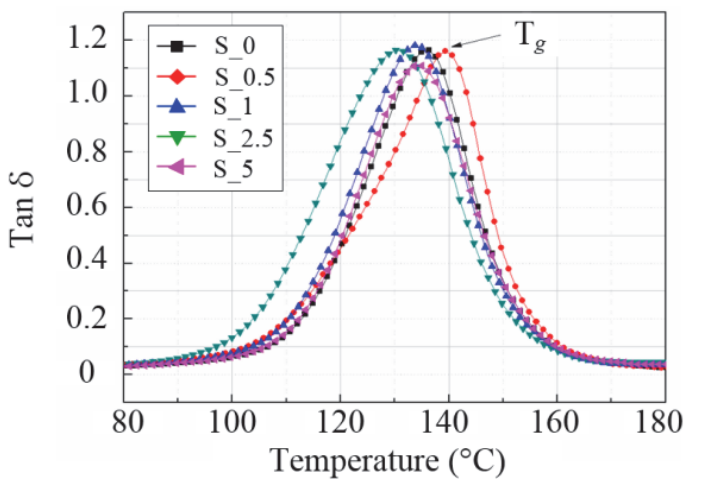

Figure 6. $T_{g}$ measurement results of pure $\mathrm{EP}$ and $\mathrm{EP} / \mathrm{SiO}_{2}$.

\subsection{BREAKDOWN ELECTRIC FIELD STRENGTH}

According to the Weibull distribution, the cumulative probability $P$ of electrical breakdown can be expressed as:

$$
P(x)=1-\exp \left[-\left(\frac{E}{\alpha}\right)^{\beta}\right]
$$

where $\alpha$ and $\beta$ represent scale and shape parameters, and $E$ represents short-term breakdown electric field strength. The Weibull distribution of breakdown strength of epoxy resins with the different nano-particle content at room temperature is shown in Figure 7.

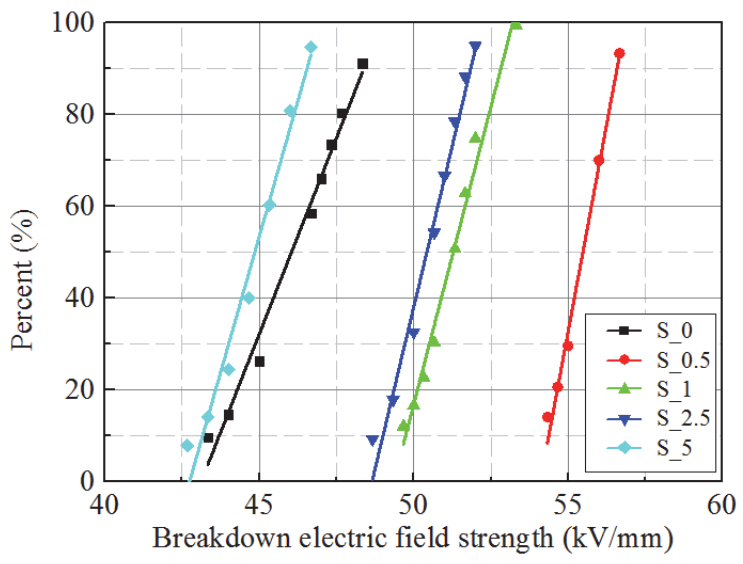

Figure 7. Weibull distribution of AC Breakdown strength

It can be seen that the dielectric strength of epoxy resin is significantly changed after the introduction of nano- $\mathrm{SiO}_{2}$. The breakdown strength of EP nanocomposites increases first and then decreases with the increase of nano- $\mathrm{SiO}_{2}$ content. When the content of nano-particle is $0.5 \mathrm{wt} \%$, the breakdown strength of the nanocomposite reaches the highest value which is about $19.0 \%$ higher than the one of pure EP. It can be seen from Table 1 that the scale parameter is consistent with the variation law of breakdown strength, while the addition of nanoparticles leads to the increase of the shape parameter. For example, when the content of nano particles is $0.5 \mathrm{wt} \%$, the shape parameter is 2 times higher than the one related to the pure epoxy resin. The best result is achieved when the content of nanoparticles is $0.5 \mathrm{wt} \%$, which is more than 2 times of pure epoxy resin. This indicates that the addition of nano- $\mathrm{SiO}_{2}$ reduces the dispersion of breakdown strength and makes the internal structure of the material more compact.

Table 1. Weibull distribution parameters of AC breakdown.

\begin{tabular}{llllll}
\hline & S_0 & S_0.5 & S_1 & S_2.5 & S_5 \\
\hline$\beta$ & 29.10 & 68.51 & 51.65 & 51.72 & 39.90 \\
$\alpha$ & 46.87 & 55.85 & 51.68 & 50.91 & 45.42 \\
\hline
\end{tabular}

Figure 8 shows the curve of $\mathrm{AC}$ dielectric strength as a function of temperature for samples characterized by different content of nanoparticles. It can be noticed that the AC dielectric strength of all samples gradually decreases with the increase of 
temperature. When the temperature is higher than $120^{\circ} \mathrm{C}$, the $\mathrm{AC}$ dielectric strength decreases faster with respect to lower temperatures. Moreover, the breakdown electric field strength of S_0.5 results is higher than the one of the other samples, especially when temperature is more than $120^{\circ} \mathrm{C}$.

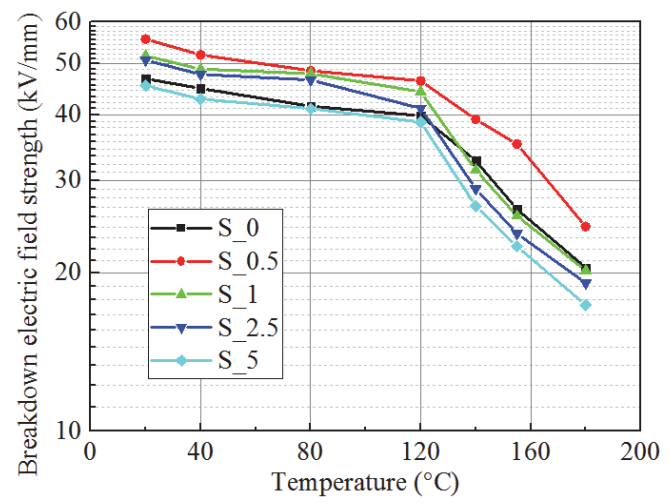

Figure 8. AC dielectric strength at different temperatures.

\subsection{CHARACTERIZATION OF 6 KV STATOR COILS DOPED WITH 0.5 WT\% NANO-SIO}

Figure 9 shows the trend of the dissipation factor of experimental stator coils at different temperatures for doped sample with $0.5 \mathrm{wt} \%$ nano- $\mathrm{SiO}_{2}$, where it is shown that the dielectric losses of both coils increase with temperature. This trend is more pronounced when the temperature is above $120{ }^{\circ} \mathrm{C}$. Coils doped with nanoparticles at different temperatures have lower dielectric losses, especially for temperatures above $120^{\circ} \mathrm{C}$.

Moreover, the dissipation factor tip-up per kilo volt was calculated by

$$
\Delta \tan \delta=\tan \delta_{\mathrm{HV}}-\tan \delta_{\mathrm{LV}}
$$

where $\tan \delta_{\mathrm{HV}}$ and $\tan \delta_{\mathrm{LV}}$ respectively represent the value of dielectric loss between each successive voltage value. For example, $\tan \delta$ at $1 \mathrm{kV}$ has been subtracted from tan $\delta$ at $2 \mathrm{kV}$, and $\tan \delta$ at $6 \mathrm{kV}$ has been subtracted from $\tan \delta$ at $7 \mathrm{kV}$.

The dependency of dissipation factor tip-up per kilovolt versus temperature has been reported in Figure 9b. When temperature is higher than about $120^{\circ} \mathrm{C}$, the dissipation factor tip-up of the mica coil is clearly larger than that of the nanocomposite coil. At $155{ }^{\circ} \mathrm{C}$, the dissipation factor tip-up of the mica coil is about $2.6 \% / \mathrm{kV}$, while the dissipation factor tip-up of the nanocomposite coil is $2.1 \% / \mathrm{kV}$. Therefore, nano-fillers can reduce the dielectric loss of the coil to a certain extent, especially when local temperature increases.

Figure 10 shows the leakage current curve of the two coils at $5 \mathrm{kV}$ DC at $25{ }^{\circ} \mathrm{C}$ (measurement system winding connection is the same as Figure 3). It is worth noting that the leakage current of both coils decays with time and the current stability value of the nanocomposite coil results less than 0.3 $\mathrm{nA}$ (lower than $0.8 \mathrm{nA}$ of the undoped coil). Considering the stabilized current value to calculate the insulation resistance, the insulation resistance of the undoped coil and the doped coil are about 5 9 $\mathrm{T} \Omega$ and $25 \mathrm{~T} \Omega$, respectively. Therefore, the insulation resistance of the coil is slightly increased after doping the nanoparticles.
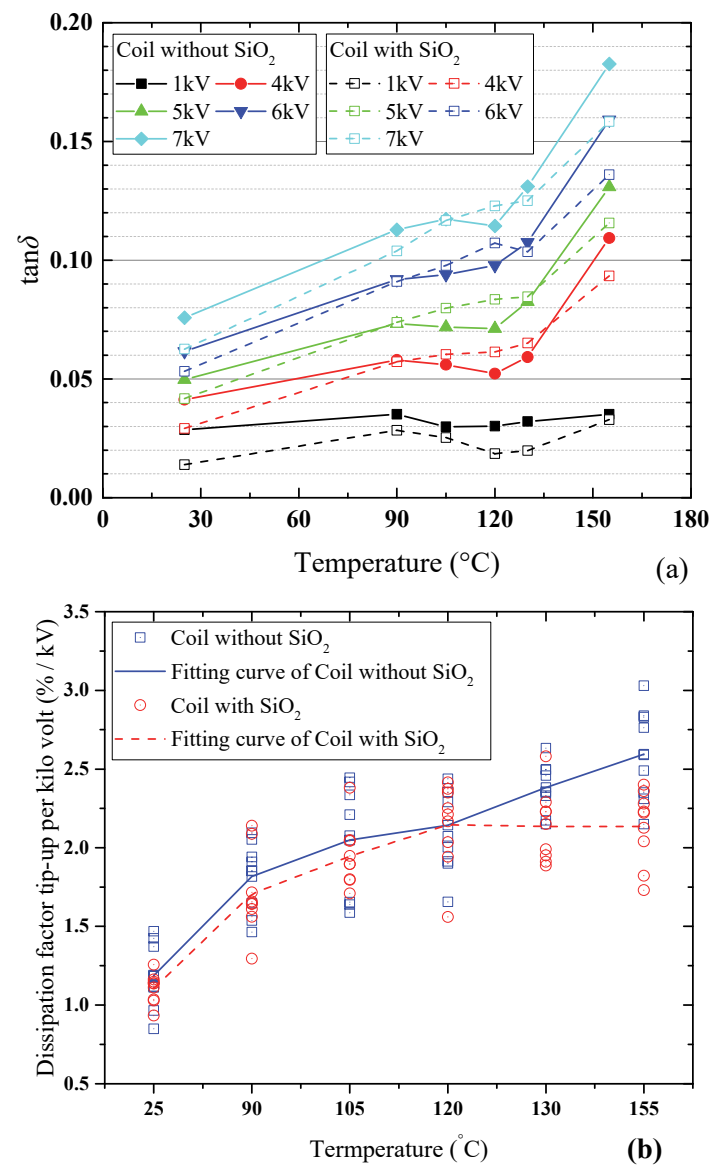

Figure 9. Under different voltages and temperatures: samples' (a) dissipation factor and (b) dissipation factor tip-up.

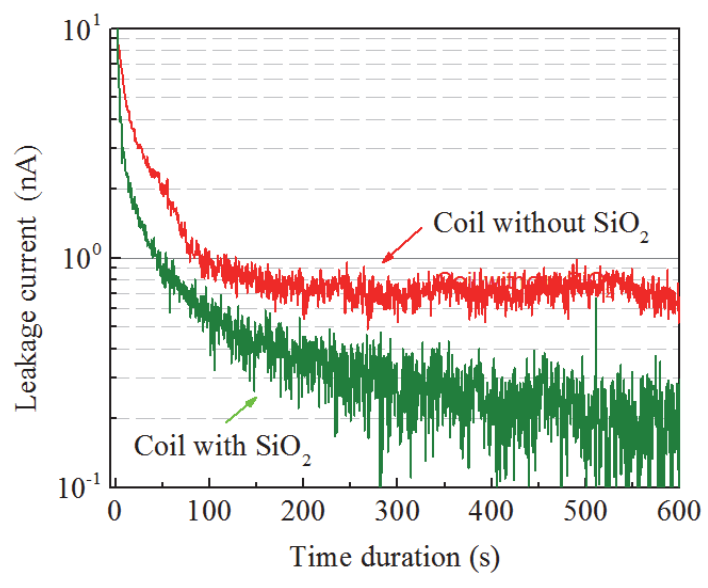

Figure 10. Leakage current of stator coil under DC voltage.

\subsection{PARTIAL DISCHARGE ANALYSIS}

Figure 11 shows the PRPD of the pure stator coil and the nano- $\mathrm{SiO}_{2}$ doped stator coil at $2 \mathrm{kV}$ and $6 \mathrm{kV}$, respectively. It can be found that the doping of $\mathrm{SiO}_{2}$ has potential effects on the inner discharge and the partial discharge on the surface. As an example, when $2 \mathrm{kV}$ was applied, some PDs occurred in the positive half voltage cycle with the amplitude of $10 \mathrm{pC}$ for 
the nano $\mathrm{SiO}_{2}$ doped coil. This phenomenon can be due to PDs taking place within small voids inside the main wall insulation. Moreover, when the voltage is up to $6 \mathrm{kV}$, PDs in the triple junction between the insulation, the air, and the grounded metal can be detected for the nano- $\mathrm{SiO}_{2}$ doped coil. Similarly, for the pure coil, PDs can also be found at $6 \mathrm{kV}$. However, the repetition rate for the PD pulses with the amplitude ranging from $100 \mathrm{pC}$ to $5000 \mathrm{pC}$ for pure stator coil is much higher than the nano- $\mathrm{SiO}_{2}$ doped stator coil. It is known that the glass-reinforced epoxy mica can withstand inter-
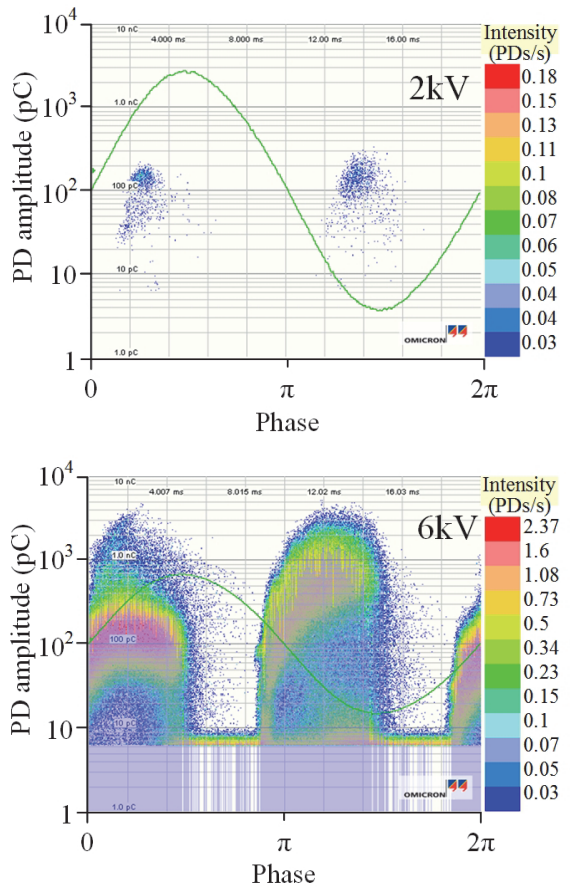

(a) PRPD of stator coils without nanoparticles
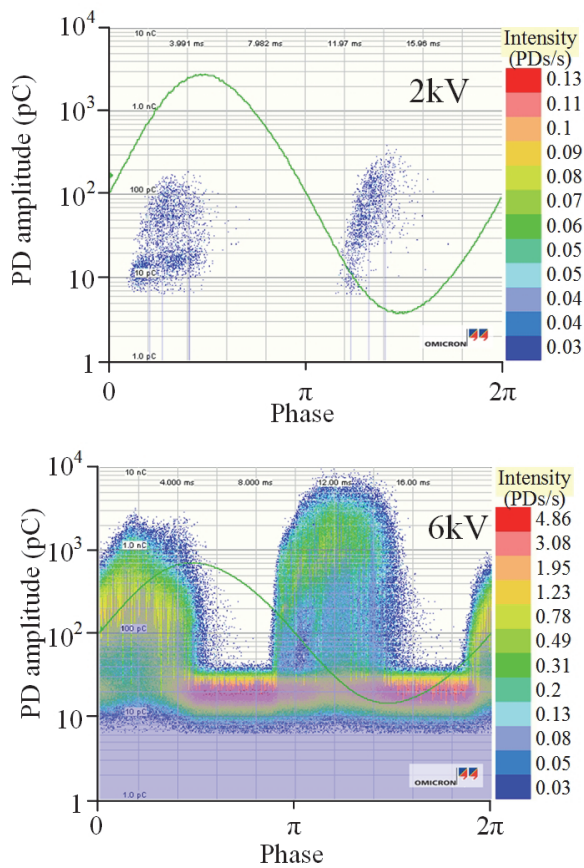

(b) PRPD of stator coils with nanoparticles

Figure 11. PRPD of stator coils at different voltages. nal discharge for decades, while surface PDs in the winding could have more energy, which can be a potential disadvantage for the safe operation of the HV machine [15].

\section{MECHANISMS FOR PROPERTY IMPROVEMENT}

\subsection{GRAFTING OF NANOPARTICLES}

Figure 12 shows the FTIR spectra of the investigated samples. There is a distinct absorption peak at $805 \mathrm{~cm}^{-1}$, which corresponds to the stretching vibration of $\mathrm{Si}-\mathrm{O}-\mathrm{Si}$ bond [16]. Absorption peaks at $1630 \mathrm{~cm}^{-1}$ can be found in all samples, corresponding to the bending vibration of hydroxyl $(-\mathrm{OH})$. This indicates that either the surface of nanoparticles Hydroxyl groups are present on the surface of the particles, or water molecules are adsorbed on the surface of the particles [17]. The sample after doping with $\mathrm{SiO}_{2}$ shows a lower absorption peak than the undoped sample. Moreover, the doped sample has a distinct absorption peak at $2921 \mathrm{~cm}^{-1}$, corresponding to the stretching vibration of $\mathrm{C}-\mathrm{H}$ in the coupling agent [18]. The coupling agent can react with $-\mathrm{OH}$ on the surface of $\mathrm{SiO}_{2}$ to form a $-\mathrm{Si}-\mathrm{O}-\mathrm{Si}$ covalent bond, thereby to produce a stronger connection. The methylene group in KH550 showed a distinct peak at $1250 \mathrm{~cm}^{-1}$ compared to the undoped sample, indicating that KH550 has successfully modified the nano- $\mathrm{SiO}_{2}$ particles. The peaks of S_2.5 and S_5 near $3500 \mathrm{~cm}^{-1}$ do not significantly vary compared with pure EP. The possible reason could be found in the content of nanoparticles. The increase in their concentration, in fact, leads to the agglomeration of the particles resulting in a wider interface region.

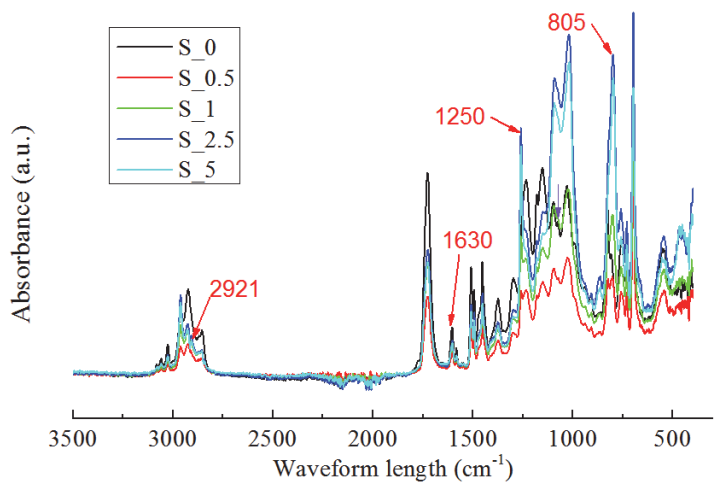

Figure 12. FTIR of spectra of experimental samples.

\subsection{DIELECTRIC STRENGTH MODIFICATION}

The trap distribution of EP nanocomposites is shown in Figure 13. When the content of nanoparticles increases from $0 w t \%$ to $5 \mathrm{wt} \%$, both the level and density of shallow traps initially increase, then decrease. However, the depth of the traps nanocomposites stays still higher than pure EP. When the contents are $0.5 \mathrm{wt} \%$ and $1 \mathrm{wt} \%$, the increase of shallow traps depth and density will affect the carrier migration process inside the material. The deep traps level also rises with the content of nano-particles. 


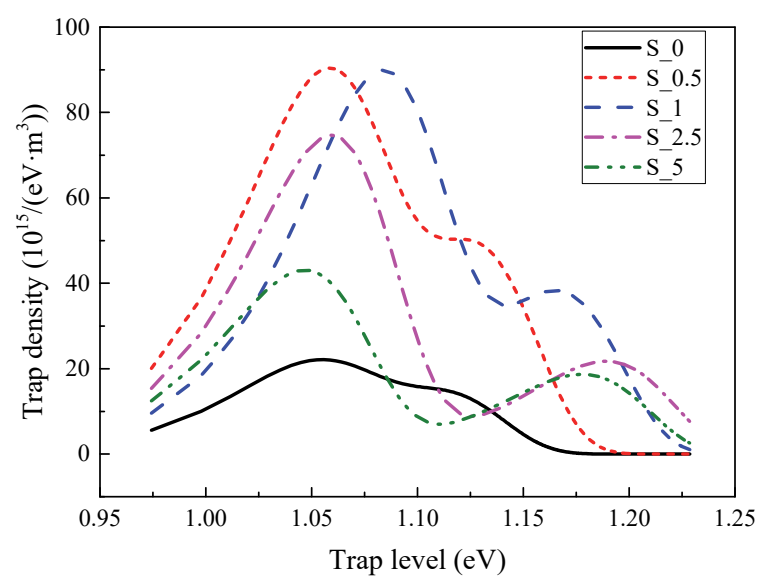

Figure 13. Trap distribution of EP nanocomposites.

The effect of nano- $\mathrm{SiO}_{2}$ on the dielectric strength of EP is closely related to the interface regions formed between the EP matrix and the nano-fillers. The hydroxyl groups on the surface of the nano- $\mathrm{SiO}_{2}$ react with the hydroxyl groups from hydrolysis of the coupling agent, which forms a Si-O-Si bond. The other end of the coupling agent reacts with the EP to form a covalent bond. In Figure 14, the nano- $\mathrm{SiO}_{2}$ particles are presented as blue spheres. The nano- $\mathrm{SiO}_{2}$ and EP matrix combine by the mean of a coupling agent leading to a large number of interfacial regions in the material. According to the multi-region structure of spherical nano-particles [19], the interface region consists of bonded region and transition region, as shown in Figure 15. Polymer chains are arranged randomly in epoxy matrix, and relatively orderly in the interfacial region, bringing to a relatively high conduction region in the transition region.

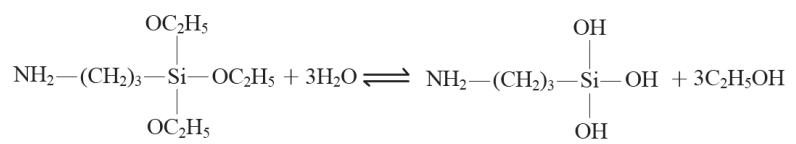

(a) Hydrolysis of coupling agent KH550

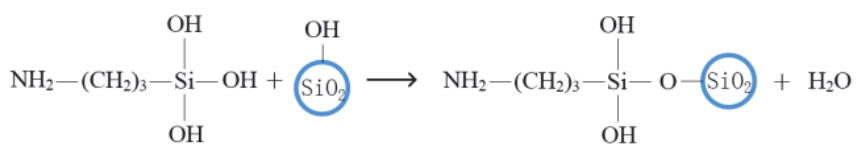

(b) Coupling agent $\mathrm{KH} 550$ reacts with $\mathrm{SiO}_{2}$
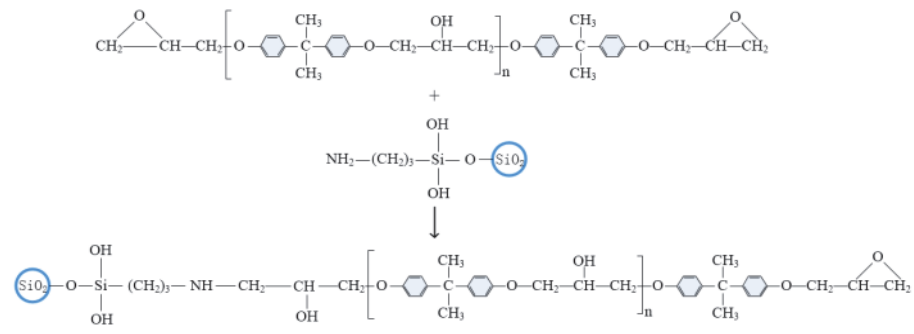

(c) EP reacts with $\mathrm{SiO}_{2}-\mathrm{KH} 550$

Figure 14. Reaction of silane coupling agent with $\mathrm{EP}$ and nano- $\mathrm{SiO}_{2}$

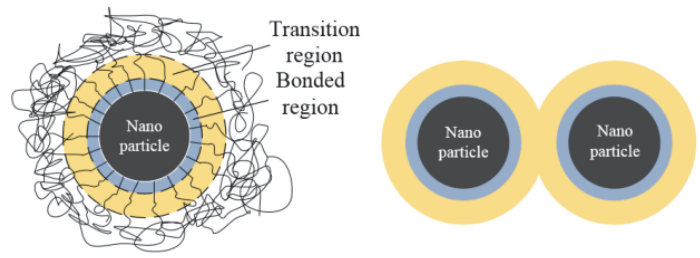

(a) Interface of isolated particles and overlapped interfaces of adjacent particles

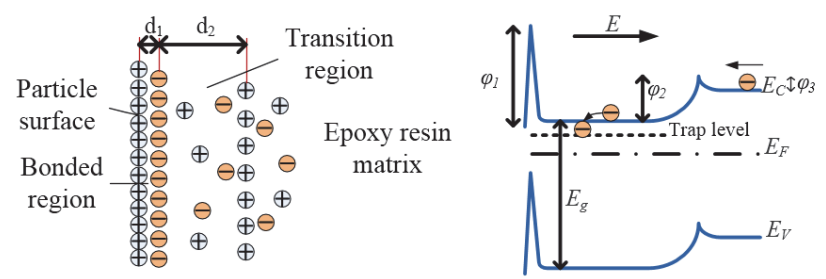

(b)Barrier model around isolated particle when an electric field is applied
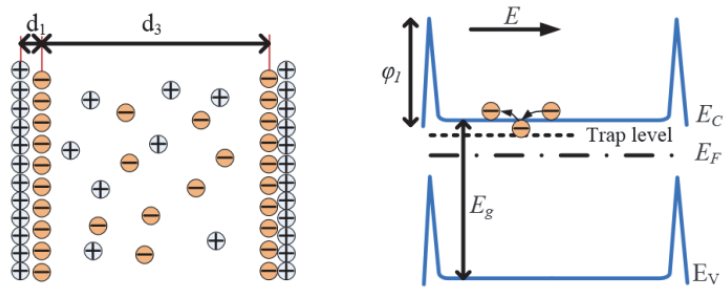

(c) Barrier model in which adjacent particle boundaries overlap when an electric field is applied

Figure 15. Potential barrier model around nanoparticles.

When nanoparticles are evenly dispersed in the epoxy resin matrix, the relationship between nanoparticle spacing and specific surface area and the content of nano- $\mathrm{SiO}_{2}$ can be expressed as follows [20],

$$
\begin{gathered}
D=d\left\{\left\{\frac{\pi 100 \rho_{1}}{6 C \rho_{2}}\left[1-\frac{C}{100}\left(1-\frac{\rho_{2}}{\rho_{1}}\right)\right]\right\}^{1 / 3}-1\right\} \\
S=\frac{\pi d^{2}}{(D+d)^{3}}=\pi\left(\frac{d}{D+d}\right)^{2} \frac{1}{D+d}
\end{gathered}
$$

where $d$ is the diameter of nano-particles; $D$ is the spacing between nano-particles; $S$ is the specific surface area of nanoparticles; $\rho_{1}$ and $\rho_{2}$ represent the density of nano-particles and EP; $C$ represents the mass fraction of nano-particles.

When the content of nanoparticles is lower than $1 \mathrm{wt} \%$, it can be seen from the equation (5) and (6) that with the increase of the nanoparticles, the spacing $D$ of nanoparticles decreases rapidly, the specific surface area $S$ increases gradually, and the proportion of the internal interface area per unit volume increases gradually. According to the multi-core model for polymer nanocomposite [21], the increase of the volume of the interface region leads to an increase in carrier trapping probability during the migration process. On the other hand, it can be seen from the trap distribution that the addition of lowcontent nanoparticles greatly increases the depth and density of traps in the matrix. It is generally believed that traps can capture carriers and thus inhibit the transfer of carriers. 
The charge distribution and potential energy barrier model near the nanoparticles are shown in Figure 15, where EC stands for the bottom of the conduction band and $E_{V}$ for the top of the valence band, while $E_{F}$ and $E_{g}$ stands for Fermi energy level and forbidden band, respectively [22]. It is worth noting that a strong internal electric field exists in the bonded region on the surface of nano-particles. The width and barrier height of the bonded region are $d_{1}$ and $\phi$, respectively. The corresponding space charge layer and its barrier heights between the interface region and the matrix are $d_{2}$ and $\phi$, respectively. To maintain the electrical neutrality around nanoparticles, some net charges accumulate in the matrix near the interface region and compensate for the charges captured in both the bonded region and the transition region, which forms a potential barrier $\phi$. Due to the low height of the barrier $\phi$, the carriers in the matrix can easily jump through $\phi$ into the transition region under the action of an external electric field. It can be seen from the trap level distribution that there are a large number of deep traps in the transition region when the content of nanoparticle is low. On the one hand, the carriers entering the transition region can be trapped, or collided with the traps and lose part of energy. On the other hand, the average free path of charge carriers in most of cases is larger than the thickness of the interface regions. In fact, the carriers cannot get enough energy from the external electric field to jump over the barrier. As a consequence, the carriers are trapped and cannot participate in the conduction. It can also be seen from the conductivity test results in Figure 5 that the addition of low-content nano-particles reduces the conductivity of EP, which provides the evidence that the carrier mobility in the material decreases and the breakdown strength increases.

When the content of nano particles is higher than $2.5 \mathrm{wt} \%$, the interface regions formed by nano particles are overlapped. Therefore, the thickness of the transition region is increased. When the thickness of the transition region is larger than the average free path of the carriers, charge carriers in the electric field can obtain sufficient energy and jump over the barrier into the matrix. Since the shallow trap level and density of samples with higher doping ratio are reduced, the interface region acts as a relatively high conduction region. Carriers transfer along the transmission channel and obtain higher energy, which results in the increase of mobility and the decrease of breakdown strength.

\subsection{BREAKDOWN PROPERTY REGULATION AT DIFFERENT TEMPERATURES}

The dielectric strength of EP decreases gradually with the increase of temperature; also, the decreasing rate of $\mathrm{AC}$ dielectric strength of EP increases significantly when the temperature is higher than $120{ }^{\circ} \mathrm{C}$. According to the free volume breakdown theory [23], in the case of electronic breakdown, the breakdown strength $E_{b}$ can be expressed as:

$$
E_{b}=\frac{E_{\mu}}{e l_{E}}
$$

where e is the electron charge; $l_{E}$ is the free volume length; $E_{\mu}$ is the threshold barrier for breakdown.

In general, the free volume of materials is affected by the glass transition process. There are evident changes when temperature reaches the glass transition temperature $T_{g}$. When the temperature is lower than $\mathrm{Tg}$, the molecular chain of EP is rigid, and the EP is in the glass state. In this case, the temperature change has very little effect on the free volume. When the temperature is higher than $\mathrm{Tg}$, the molecular chain of the material becomes soft, and EP reaches a viscous flow state or a high elastic state, in which the influence of temperature change on the free volume is evident [23, 24]. It can be concluded that the glass transition temperature of EP and its nanocomposite is about $120{ }^{\circ} \mathrm{C}$. Therefore, the decreasing rate of $\mathrm{AC}$ breakdown strength varies near the temperature of $120^{\circ} \mathrm{C}$.

\section{CONCLUSIONS}

In this paper, nano- $\mathrm{SiO}_{2}$ is doped into EP and the potential application of nanocomposites in $\mathrm{HV}$ motors is investigated. Epoxy resins with different doping ratio of $\mathrm{SiO}_{2}$ are prepared and tested. The doping of nano- $\mathrm{SiO}_{2}$ with a mass ratio of 0.5 $\mathrm{wt} \%$ resulted to have a positive effect on the AC dielectric strength of EP, especially on the breakdown strength and Tg. Higher doping ratio resulted in an overlapped region between interfaces of nano particles, which leads to a decrease of the dielectric property for epoxy-based materials. In addition, a 6 $\mathrm{kV}$ stator coil was prepared and tested using doping ratio of $0.5 \% \mathrm{SiO}_{2}$. The coils doped with $\mathrm{SiO}_{2}$ with a mass ratio of $0.5 \mathrm{wt} \%$ obtained high performances over pure coils, especially in aspects such as: leakage current, PD properties, and dielectric losses. These improvements provide potential application of nano particles in HV motor insulation.

\section{ACKNOWLEDGMENT}

This work was supported by the National Natural Science Foundation of China under Grant No. 51977137 and 51577123.

\section{REFERENCES}

[1] G. C. Stone,"Partial discharge diagnostics and electrical equipment insulation condition assessment," IEEE Trans. Dielectr. Electr. Insul.,vol. 12, pp. 891-904, 2005.

[2] S. A. Boggs and G. C. Stone, "Fundamental limitations in the measurement of corona and partial discharge," IEEE Trans. Dielectr. Electr. Insul.,vol. 2, pp.143-150,1982.

[3] M. Katz and R. J. Theis, "New high temperature polyimide insulation for partial discharge resistance in harsh environments," IEEE Electr. Insul. Mag., vol. 13, pp.24-30, 1997.

[4] C. J. Zhong and M. M. Maye, "Core-shell assembled nanoparticles as catalysts,” Adv. Mater., vol. 13, pp. 1507-1511, 2001.

[5] C. Li, J. Hu, C. Lin, and J. He, "The control mechanism of surface traps on surface charge behavior in alumina-filled epoxy composites," J. Phys. D: Appl. Phys., vol. 49, 445304, 2016.

[6] H. Li, H. Xiao, J. Yuan, and J. Ou, "Microstructure of cement mortar with nano-particles," Composites Part B: Engineering, vol.35, pp.185$189,2004$.

[7] M. G. Danikas and T. Tanaka, "Nanocomposites - a review of electrical treeing and breakdown," IEEE Electr. Insul. Mag., vol.25, pp.19-25, 2009. 
[8] S. Jahani and Z. Jacob, "All-dielectric metamaterials," Nature nanotechnology, vol. 11, pp. 23-36, 2016.

[9] Weidner et al, "Nanotechnology in high voltage insulation systems for turbine generators-First results." 17th International Symposium on High Voltage Engineering, Hannover, Germany, Aug. 2011.

[10] R. Dettmer, "The heart of a new machine,"IEE review,vol.44,pp. 255$258,1998$.

[11] J. C. Song et al, "Slot discharge pattern of $10 \mathrm{kV}$ induction motor stator coils under condition of insulation degradation," IEEE Trans. Dielectr. Electr. Insul.,vol. 20, pp. 2091-2098, 2013.

[12] Z. Lei et al, "Effect of graphene coating on space charge characteristic of XLPE and semiconductive layer," IEEE Access, vol.7, pp.124540$124547,2019$.

[13] S. Bourbigot, B. M. Le, S. Duquesne, and M. Rochery, "Recent advances for intumescent polymers," Macromolecular Mat. Engineering,vol.289, pp. 499-511, 2004

[14] Y. H.Gao et al, "Recyclable dielectric polymer nanocomposites with voltage stabilizer interface: toward new generation of high voltage direct current cable insulation," ACS Sustain. Chem. Eng., vol.7, pp. 513-525, 2018.

[15] T. Shahsavarian and S. M. Shahrtash, "Modelling of aged cavities for partial discharge in power cable insulation," IET Sci. Meas. Technol., vol. 9, pp. 661-670, 2015.

[16] L. H. Cheng et al, "Influence of particle surface properties on the dielectric behavior of silica/epoxy nanocomposites," Physica B, vol. 403, pp. 2584-2589, 2008.
[17] P. Liu et al, "Characteristics of space charge distribution in epoxy-paper composite insulation system.," IEEE Trans. Dielectr. Electr. Insul., vol. 23, pp. 2385-2392, 2016.

[18] P. Maity et al, "Improvement in surface degradation properties of polymer composites due to pre-processed nanometric alumina fillers," IEEE Trans. Dielectr. Electr. Insul., vol. 15, pp. 63-72, 2008.

[19] Y. Y. Li, M. Q. Tian, Z. P. Lei, and J. H. Zhang, "Effect of nano-silica on dielectric properties and space charge behavior of epoxy resin under temperature gradient," J. Phys. D: Appl. Phys., vol. 51, pp. 125309, 2018.

[20] S. T. Li et al, "Short-term breakdown and long-term failure in nanodielectrics: a review," IEEE Trans. Dielectr. Electr. Insul., vol. 17, pp. $1523-1535,2010$.

[21] T. Tanaka, M. Kozako, N. Fuse, and Y. Ohki, "Proposal of a multi-core model for polymer nanocomposite dielectrics," IEEE Trans. Dielectr. Electr. Insul., vol. 12, pp. 669-681, 2005.

[22] S. T. Li, G. L. Yin, S. N. Bai, and J. Y. Li, "A new potential barrier model in epoxy resin nanodielectrics," IEEE Trans. Dielectr. Electr. Insul., vol. 18, pp. 1535-1543, 2011.

[23] Q. Li et al, "High energy and power density capacitors from solutionprocessed ternary ferroelectric polymer nanocomposites," Adv. Mater., vol. 26, pp. 6244-6249, 2014.

[24] Z. Li, Z. Zhong, and B. Du., "Dielectric relaxation and trap-modulated DC breakdown of polypropylene blend insulation," Polymer, vol. 185, pp. 1-9, 2019. 